\title{
EVALUATION OF DYE INJECTION METHODS IN CONGENITAL HEART DISEASE
}

\author{
BY \\ WALTHER FALHOLT AND JØRGEN FABRICIUS \\ From the Medical Clinic B, Rigshospitalet (Physician-in-Chief, Professor Erik Warburg), University of Copenhagen \\ Denmark
}

Received August 30, 1957

Obtaining dye dilution curves after injection of Evans blue dye into the circulation has been greatly facilitated through the introduction of direct recording colorimeters. These allow for continuous sampling of blood from a systemic artery or through a cardiac catheter, and registration of the dye curve either photographically or by a direct writing system (Friedlich et al., 1950; Shadle et al., 1953; and Falholt and Kaiser, 1955).

The colorimeters have the advantage over ear oximeters, constructed for the same purpose, that concentrations of dye are registered more centrally in the circulation from a brachial or femoral artery, so that distortion of the dye curves due to laminar flow in the smaller arteries and capillaries is avoided. Further disadvantages of the ear oximeters hitherto constructed are erroneous deflections due to instability in the fixation of the ear-piece, and deflections independent of the momentary dye concentration caused by spontaneous fluctuations in oxygen saturation of the blood. In acyanotic cases of congenital heart disease this cause of error in dye concentrations measured may be diminished by letting the patient inspire pure oxygen (Swan et al., 1953), but in cyanotic cases this attempt at correction is not permissible.

The dye colorimeter used in the present observations automatically corrects for changes in oxygen saturation of the blood sampled (Falholt and Kaiser, 1955).

\section{MeThODS}

In all cases of congenital heart disease in which dye dilution curves were obtained, this procedure was performed at the end of cardiac catheterization, after the diagnosis was established. Evans blue dye, T-1824, was injected through the cardiac catheter, when the tip of the catheter was at the position in the heart or pulmonary artery, where the injection of dye was expected to give a dilution curve most characteristic of the particular malformation. The amount of dye injected was roughly estimated from the size of the patient, and the size and direction of the shunt, as determined from the catheter findings, and 5 to $30 \mathrm{mg}$. of dye were injected as rapidly as possible. The catheter was filled with dye 3 to 5 minutes before the injection, so that the actual amount of dye entering the circulation during the registration of the dye curve was identical with that leaving the syringe. In this way the necessity of correcting for the dead space in the catheter was avoided.

Puncture of the brachial or femoral artery was performed immediately before the final injection of dye, with a needle connected with a $15 \mathrm{~cm}$. long plastic tube leading to the dye colorimeter. The dye curves were registered on $12 \mathrm{~cm}$. wide paper, passing with a speed of $1 \mathrm{~cm}$. per second through the direct writing system of the apparatus.

The oxygen saturation of blood samples taken during cardiac catheterization was determined by the Brinkman-Zijlstra (1949) hæmoreflector and the van Slyke method. Pressure measurements were performed by the electrical condenser manometer of Hansen (1949), a development of the manometer originally designed by Buchtal and Warburg (1943). The oxygen consumption was estimated according to Boothby 
et al. (1936). Calculations of the flows and shunts were made according to Bing et al. (1947). The results obtained in the cases illustrated by the figures are seen in Table I.

TABLE I

Hemodynamic Data of the Patients shown in the Figures

\begin{tabular}{|c|c|c|c|c|c|c|c|c|}
\hline \multirow{3}{*}{ Diagnosis } & & \multirow{3}{*}{$\frac{\text { Fig. 1 }}{\begin{array}{c}\text { Fallot's } \\
\text { tetralogy }\end{array}}$} & Fig. 2 & Fig. 3 & Fig. 4 & Fig. 5 & Fig & \\
\hline & & & \multirow{2}{*}{$\begin{array}{l}\text { Pulmonary } \\
\text { stenosis } \\
\text { with } \\
\text { A.S.D. }\end{array}$} & \multirow{2}{*}{$\begin{array}{l}\text { Fallot's } \\
\text { tetralogy }\end{array}$} & \multirow[t]{2}{*}{ A.S.D. } & \multirow{2}{*}{$\begin{array}{l}\text { Pulmonary } \\
\text { stenosis }\end{array}$} & \multicolumn{2}{|c|}{ A.S.D \& A.P.V.D. } \\
\hline & & & & & & & Before op. & After op. \\
\hline $\begin{array}{l}\mathrm{O}_{2} \text { consumption (c.c./min.) } \\
\text { Systemic flow; lit./min. } \\
\text { Pulm. flow: lit./min. .. } \\
\text { Effective flow: lit./min... } \\
\text { L. to R. shunt } \quad \ldots \quad \ldots \\
\text { R. to L. shunt } \quad \ldots \quad \ldots\end{array}$ & .. & $\begin{array}{l}129 \\
7 \cdot 6 \\
2 \cdot 9 \\
2 \cdot 9 \\
0 \\
4 \cdot 7\end{array}$ & $\begin{array}{l}176 \\
5.9 \\
2.9 \\
2.9 \\
0 \\
2 \cdot 9\end{array}$ & $\begin{array}{l}180 \\
4 \cdot 4 \\
3 \cdot 2 \\
3 \cdot 2 \\
0 \\
1 \cdot 2\end{array}$ & $\begin{array}{c}264 \\
6 \cdot 5 \\
16 \cdot 5 \\
6 \cdot 5 \\
10 \cdot 1 \\
0\end{array}$ & $\begin{array}{c}258 \\
4 \cdot 5 \\
4 \cdot 3 \\
4 \cdot 3 \\
0 \\
0\end{array}$ & $\begin{array}{l}146 \\
2 \cdot 5 \\
6 \cdot 1 \\
2 \cdot 5 \\
3 \cdot 6 \\
0\end{array}$ & $\begin{array}{c}146 \\
3 \cdot 4 \\
3 \cdot 4 \\
3 \cdot 4 \\
0 \\
0\end{array}$ \\
\hline
\end{tabular}

\section{RESUlTS AND Discussion}

\section{Cyanotic Cases of Congenital Heart Disease}

The right-to-left shunt causing the cyanosis may be due to defects in the atrial or ventricular septa, to an overriding or transposed aorta, or to an abnormal communication between the great vessels, that is aorto-pulmonary defect or a patent ductus with pulmonary hypertension and partial or total reversal of the flow through the duct. Naturally the presence of a right-to-left shunt will result in a dye curve different from that found normally, when dye is injected at a place correctly chosen in relation to the site of the shunt: the larger the shunt the more pronounced this difference will be. Fig. 1 illustrates a normal dye curve (above) and one obtained in a case of Fallot's tetralogy with a considerable right-to-left shunt (below). The dye in this case was injected into the right atrium. It may be seen, that shortly after the injection an initial hump is obtained due to dye that has passed through the over-riding aorta, and 7 seconds later a further increase in concentration of

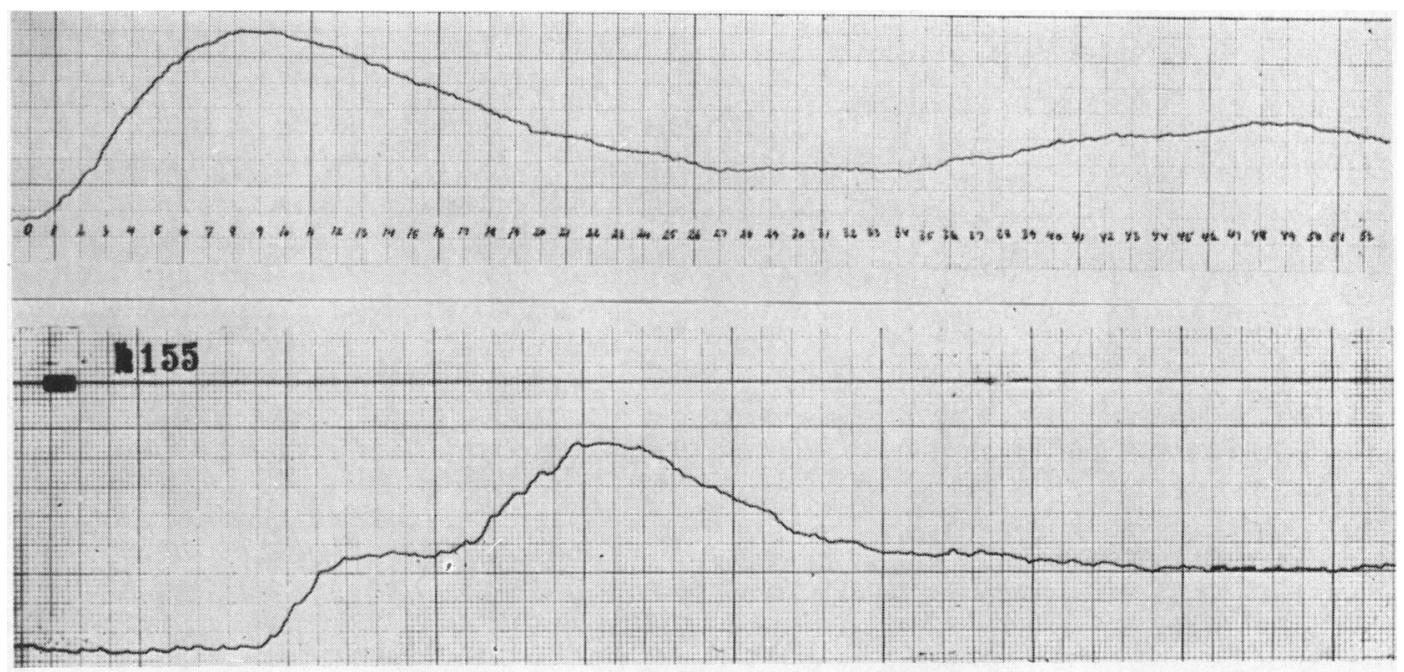

FIG. 1.-Dye dilution curves. Upper curve from a normal subject; lower curve from a case of Fallot's tetralogy with a considerable right-to-left shunt, resulting in an initial hump on the dye curve. Paper breadth $12 \mathrm{~cm}$., time between the heaviest lines 5 seconds. $15 \mathrm{mg}$. of dye were injected into the right atrium. 
dye occurs, due to dye that has passed the lungs and left side of the heart. A similar dye curve will be found in any of the heart diseases mentioned with a right-to-left shunt, provided that the dye is injected into the blood stream before the shunt. The initial hump, however, will be more or less pronounced according to the size of the shunt.

It has been suggested (Swan and Wood, 1953), that localization of the defect can be established by injection of the dye into the pulmonary artery, the right ventricle, and right atrium, successively. This may be true in certain instances, as when making the differential diagnosis between Eisenmenger's complex and a patent ductus with a reversed shunt. This differential diagnosis, however, can practically always be established by cardiac catheterization alone (generally by direct catheterization of the duct which in this case is always wide, or of the overriding aorta). It is our experience that the dye injection method is unreliable when used for distinguishing between an atrial septal defect in combination with pulmonary stenosis and a ventricular septal defect in Fallot's tetralogy.

Fig. 2 illustrates a case of pulmonary stenosis and atrial septal defect, in which the dye was injected into the right ventricle and blood sampled from a femoral artery. In spite of the injection of the dye into the right ventricle, an initial hump, similar to that found in cases of Fallot's tetralogy,

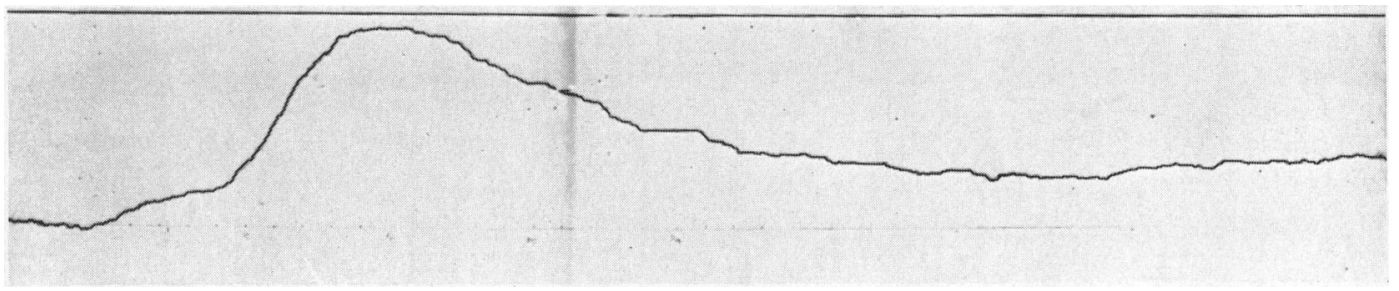

Fig. 2.-Dye dilution curve from a case of pulmonary stenosis with a defect of the atrial septum. The dye was injected through a cardiac catheter into the right ventricle and blood was sampled from a femoral artery $(20 \mathrm{mg}$. of dye injected).

was obtained. Catheterization findings gave no evidence of overriding of the aorta, ventricular septal defect, nor abnormal communications between the great vessels. The pressure in the right ventricle was $182 /-3$ and in the systemic arteries $110 / 80 \mathrm{~mm}$. $\mathrm{Hg}$, which excludes the diagnosis of Fallot's tetralogy (Gøtzsche et al., 1952). The initial hump found in this case is explained as the result of a slight tricuspid incompetence, resulting in passage of dye from the right ventricle into the right atrium, and further on through the atrial septal defect via the left heart to the aorta, before the dye passing through the lungs has reached so far. We, therefore, do not use the dye injection method diagnostically in cases of Fallot's tetralogy and pulmonary stenosis with a defect of the atrial septum, as we consider the results obtained by cardiac catheterization and possibly angiocardiography sufficient and more reliable.

In cases of congenital heart disease accompanied by very small right-to-left shunts, the interpretation of the dye curve is even more questionable. A case of Fallot's tetralogy with a rather small left-to-right shunt is seen in Fig. 3.

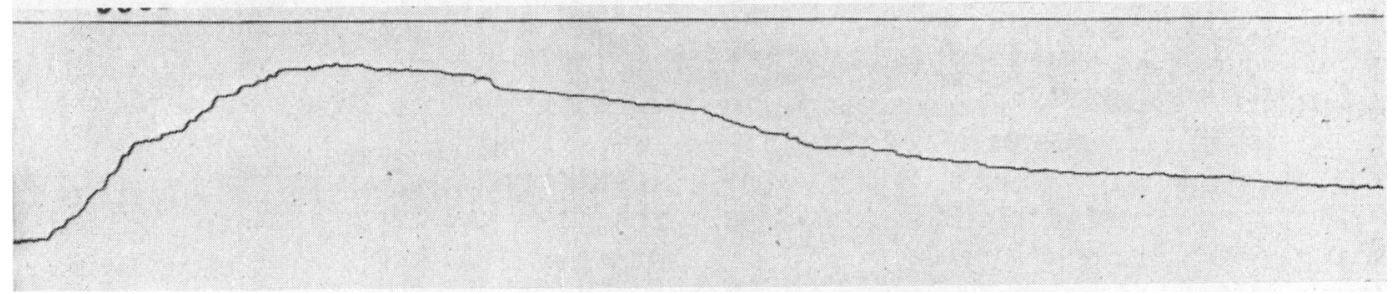

FIG. 3.-Dye dilution curve from a case of Fallot's tetralogy with a rather small right-to-left shunt. The initial hump is only slightly indicated. 
Such dye curves have been used for estimation of the right-to-left shunt in congenital heart disease (Swan et al., 1953). The formulae given are based upon so many assumptions and the introduction of correction factors, which are not even constant from one case to another, that these calculations cannot be considered of any practical value. The curves are composed of portions of dye passing through the defect and portions passing the normal way. As one can not distinguish between these portions a mathematical analysis of the curves is impossible. Direct visual inspection of the dye curves, however, may give a rough estimate of the magnitude of the shunt.

\section{Acyanotic Cases of Congenital Heart Disease}

This group of congenital heart diseases includes those with a pure left-to-right shunt and those without any shunt. The dye injection method cannot be expected to be of value in cases with no shunt, except by excluding the presence of any shunt. Small shunts, however, cannot be diagnosed reliably by this method.

Broadbent and Wood (1954) maintained that cases of left-to-right shunt of sufficient magnitude show a typical pattern of the dye curve. The characteristics are: (1) an appearance time (time between injection of the dye and the beginning of the upstroke of the dye curve) and a build-up-time (duration of the upstroke) of normal duration; (2) a maximum of dye concentration that is lower than would be anticipated in a normal dye curve; (3) an elongation of the disappearance slope (downstroke of the dye curve); and (4) absence of the peak indicating recirculation of dye. (Note the secondary peak on the normal curve in Fig. 1.) This configuration of the dye curve was found in all cases of more pronounced left-to-right shunt in atrial septal defect, abnormal pulmonary venous drainage to the right side of the heart, ventricular septal defect, and patent ductus. This characteristic pattern of dye curve, therefore, is of no differential-diagnostic value, but only indicates the presence of a left-to-right shunt (Fig. 4).

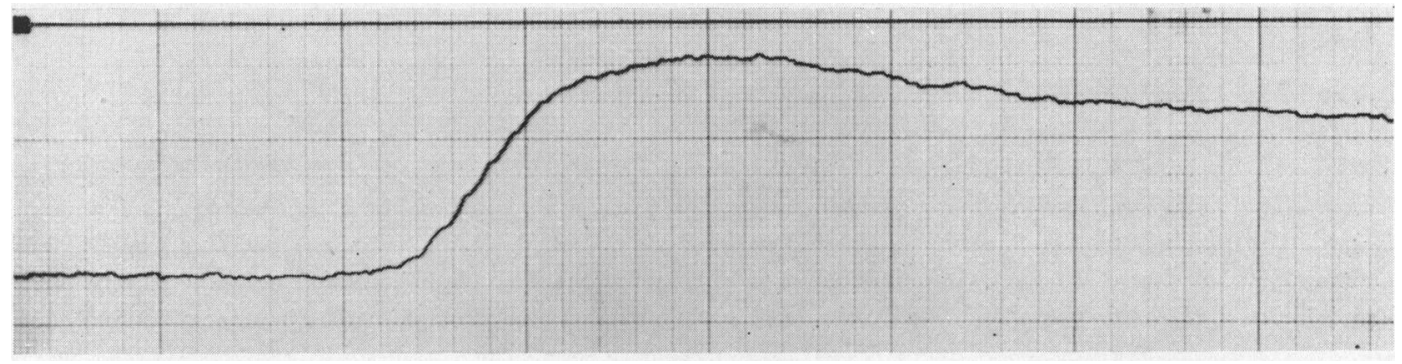

FIG. 4.-Dye dilution curve from a case of atrial septal defect with a large left-to-right shunt. (20 mg. of dye injected.)

Considering the first point: the appearance time is dependent upon the velocity of blood flow and the volume of blood between the site of injection and registration. The appearance time, therefore, is highly variable from one case to another, especially when dye is injected into an antecubital vein instead of through a cardiac catheter into the heart. The build-up-time will be discussed later. Because of the shunting of blood from left to right it is quite logical that the maximum of the dye curve will be relatively small, as blood and dye are steadily recirculating in the lesser circulation, and dye therefore only gradually reaches the aorta. This is also an explanation of the slow decrease of dye concentrations on the dilution curve. Absence of the peak due to recirculation is understandable, as systemic recirculation is diminished because of the shunting of blood from left to right, and the prolonged dilution of dye. Absence of the recirculation peak is not pathognomonic for left-to-right shunts.

The configuration of the dye curve described may be found in certain other conditions than those mentioned, such as low cardiac output, congestive heart failure, and even in pulmonary stenosis with no left-to-right shunt with low cardiac output or large residual volume in the right 
ventricle (Fig. 5). Broadbent and Wood have, therefore, suggested that the ratio of the disappearance time to the build-up-time (that is duration of downstroke/duration of upstroke) as a more reliable expression of a left-to-right shunt than the disappearance time alone. As, however, the build-up-time is normal in cases of left-to-right shunt (i.e. independent of the presence of a left-toright shunt) and, furthermore, the duration of the upstroke of the dye curve is dependent upon the volume of blood in the central veins (the dye was injected into an antecubital vein), the volume of blood in the heart and lungs, and not least the rate of injection, the value of this ratio seems doubtful.

As in any case cardiac catheterization is necessary for localizing the abnormal arterio-venous communication and gives sufficient and reliable information for calculation of the shunts with fair exactness by the Fick principle (Bing et al., 1947), the dye injection method can hardly be considered of any diagnostic value in cases of acyanotic heart disease.

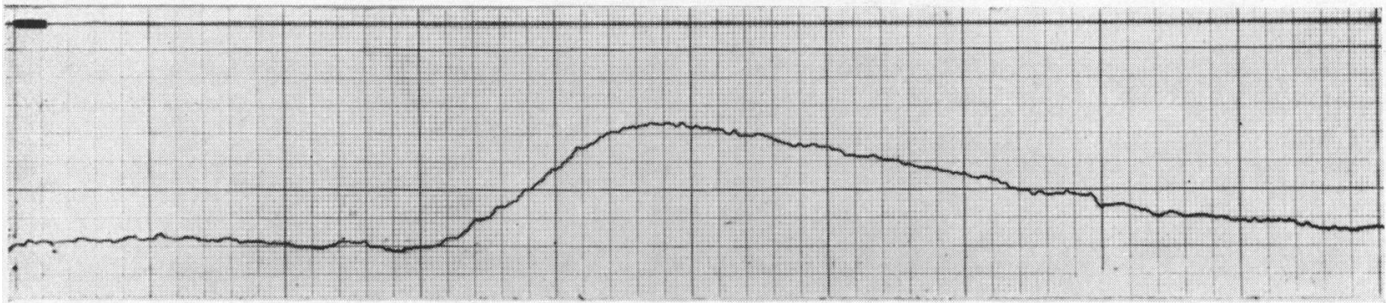

FIG. 5.-Dye dilution curve from a case of pure pulmonary stenosis. The curve shows the same pattern as in cases of congenital heart disease with a left-to-right shunt. Time and duration of dye injection $(20 \mathrm{mg}$.) is marked in the upper left corner.

It is our experience, however, that the dye injection method used on a comparative basis may give important information concerning the physiological conditions, especially when judging the result of attempts at surgical correction of cardiac malformations. This is illustrated in Fig. 6. The dye curves shown were obtained in a patient with atrial septal defect and two pulmonary

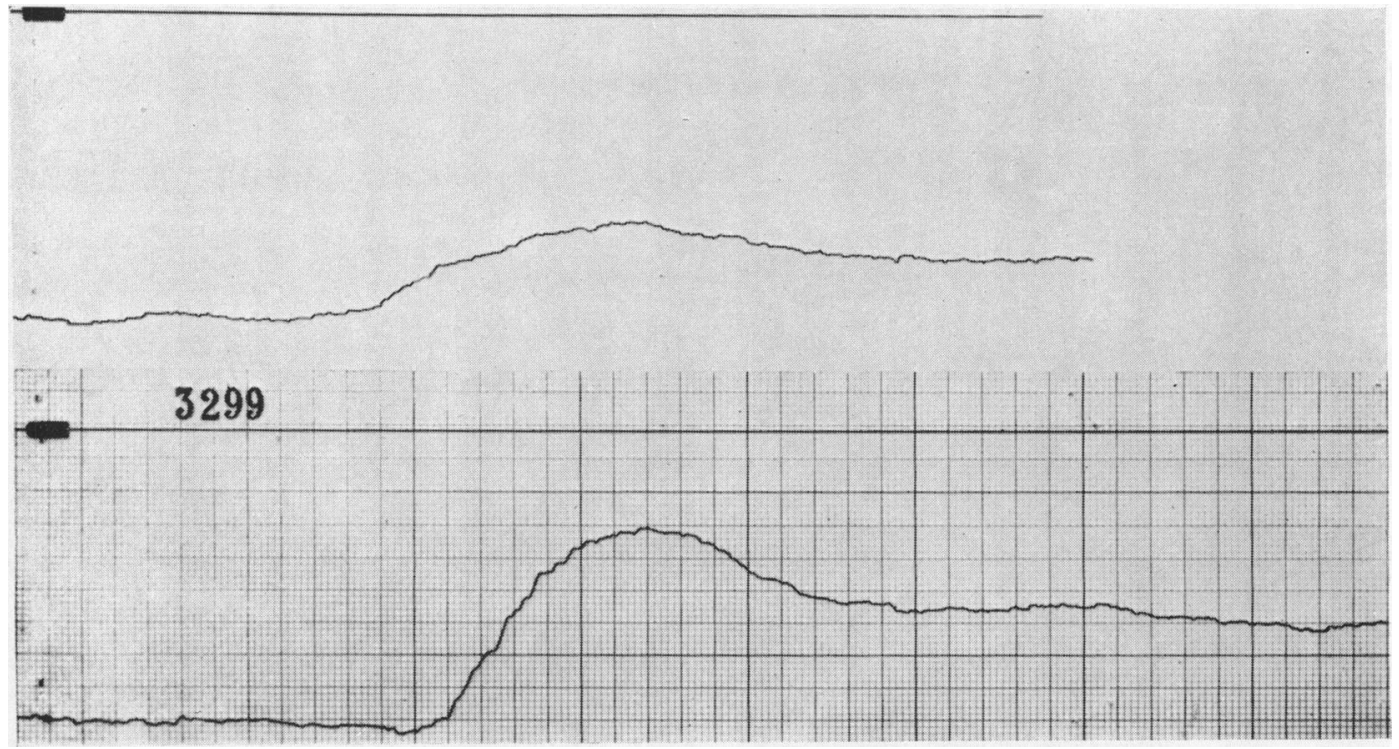

Fig. 6.-Dye dilution curves obtained in a case of atrial septal defect and two pulmonary veins draining abnormally into the right atrium, before (upper curve) and after operation by Biörk's method (lower curve). Further explanation is found in the text. 
veins draining abnormally the right atrium. The upper curve was obtained before operation: $15 \mathrm{mg}$. of Evans blue dye was injected through a cardiac catheter into the left atrium, and blood was sampled from the femoral artery. After the operation (lower curve) $10 \mathrm{mg}$. of dye were injected into the right atrium: in spite of the smaller quantity injected and the injection into the right instead of the left atrium, a considerably higher maximal concentration, a steeper dilution, and an indication of a recirculation peak were obtained as evidence of satisfactory result of the operation.

\section{SUMMARY}

The introduction of whole blood colorimeters for continuous registration of Evans blue dye concentrations has made it much easier to obtain dye dilution curves in human subjects.

Our attempt at using the dye injection method diagnostically in congenital heart disease has been disappointing, and only exceptionally does it give information that was not obtained by cardiac catheterization or angiocardiography. The dye injection method, however, is a valuable and easy method of judging the circulatory conditions before and after operations for congenital heart disease associated with left-to-right or right-to-left shunts.

\section{REFERENCES}

Bing, R. J., Vandam, L. D., and Gray, Jr., F. D. (1947). Bull. Johns Hopk. Hosp., 80, 107.

Boothby, W. M., Berkson, J., and Dunn, H. L. (1936). Amer. J. Physiol., 116, 468.

Brinkman, R., and Zijlstra, W. G. (1949). Arch. Chir. Neerland, 1, 177.

Broadbent, J. C., and Wood, E. H. (1954). Circulation, 9, 890.

Buchtal, F., and Warburg, E. (1943). Acta Physiol. Scand., 5, 55.

Falholt, W., and Kaiser, E. (1955). Circulation Res., 3, 469.

Friedlich, A., Heimbecker, R., and Bing, R. J. (1950). J. Applied Physiol., 1, 12.

Gøtzsche, H., Hansen, A. T., and Eskildsen, P. (1952). Acta med. Scand., Suppl., 266, 445.

Hansen, A. T. (1949). Pressure Measurements in the Human Organism. Teknisk Forlag, Copenhagen.

Shadle, O. W., Ferguson, T. B., Gregg, D. E., and Gilford, S. R. (1953). Circulation Res., 1, 200.

Swan, H. J. C., Zapata-Diaz, J., and Wood, E. H. (1953). Circulation, 8, 70.

- and Wood, E. H. (1953). Proc. Staff Meet. Mayo Clin., 28, 95. 